\title{
Basic q-analysis of MCQA for Information Security System
}

\author{
O.V. Kozlenko
}

\begin{abstract}
Article explores application methods for systems structural analysis to use in study of security in information systems, which is based on variants of general attack scenarios, features of cybersecurity culture, qanalysis, which is part of MCQA . General security system analysis usually is based on different factors, which include technical means, human-related mistakes in different ways and respond to security incidents. Q-analysis presents the basic principles of constructing model of information security systems elements connectivity on the example of two sets: set of threats and sets of security measures for information security and calculated numerical values. Elements of the two sets of are interconnected and form the basis of a system for ensuring their security. These calculations can be used to further determine overall formal assessment of security of the organization.
\end{abstract}

Keywords-Q-analysis; information attack scenarios; information security culture; information threats; MCQA.

\section{INTRODUCTION}

New mechanics of securing information in systems is requiring integrated use of all available security features at each stage of it's life cycle . All the tools, methods and measures used for information system should be rationally integrated into a single coherent mechanism, resisting not only the actions of the malicious actors, but also the errors of incompetent or inadequately trained users, staff members and also different causes. Desired level of information security is a complicated process, which consists of different intertwined organizational and technological mechanics and application of it's methods. Conceptualization of this approach involves development of a single concept as a complete set of scientific views, positions and decisions necessary for organization's information security system, as well as purposeful integration as stated by [18]. Multi-criteria Q-analysis (MCQA) on the other hand has proven particularly useful for solving problems related to complex systems, such as those created when processing medical images. This technique requires a definition of data sets and encourages to study consequences that can occur in system process. The purpose of this work is to mathematically describe role of elements of the information security system using the theory of topology algebra, method of estimating structural connectivity based on the mathematical apparatus of q-analysis.

\section{ATTACK VECTORS AND HUMAN FACTOR IN INFORMATION SECURITY}

Main prerequisite for creating a information security system is reliability, but if security as a whole is comprehensive and systematic. Optimal decision-making is the key to a successful security strategy that maximum efficiency. On the other hand, an important feature of the assessment and management of information system is the available factors of chance, inaccuracy, so mathematical model must be constructed not only in terms of the most adequate reflection of the essence of the simulated processes and phenomena, but also taking into account the conditions of uncertainty. In traditional approaches to management, all the uncertainties of natural processes are interpreted in a probabilistic sense, but in practice this is not always consistent with the nature of uncertainties, often a consequence of subjective assessments. [13] stated that threats are possible dangers of commitment of any action against an system object. Vulnerabilities, on the other hand, lead to a information security breach at particular system object. Vulnerabilities are inherent in the object, are inseparable from it and are caused by defects in it's process, functioning, properties, protocols, etc. Vulnerabilities are both hardware and organizational base.

In any information system, there is an information flow from the sender to receiver, so all attacks can be divided into two classes: passive and active. Passive is an attack without modifying the transmitted messages and moldering between sender and receiver of this messages. Purpose is usually to "listen on the wire". Active, on the other hand, is an attack, where there is an intent and ability to modify transmitted messages and/or insert new ones with malicious intent and/or change subject of communication as mentioned by [1].

Verizon conducts information security research every year [8-11] and usually divide attack scenarios into nine possible general segments. To determine concepts for our research, we need to analyze each of these scenarios separately:

- Point of Sale (POS) intrusion involves attacks on retail environments.

- Web Application Attack Scenario - malicious code targeting vulnerability in web applications. - Malware - confiscation of sensitive information through malicious programs. - Cyber espionage - incidents, that involve unauthorized access to systems and networks for seizing someone's information for espionage motive aka insider threat. - Payment Card Skimmer - scenario, that contains devices physically installed at ATM that collect data and illegally interfere with payment transactions. - Physical Theft or Loss - a case of physical media loss due to theft or behaivor. - Miscellaneous Mistakes - cases of unintentional compromising security attributes of information assets, usually do not include a malicious motive. - DOS Attack - attacks, that are aimed at disrupting network or system availability. - Insider Attack - all incidents of abuse by insiders or 
trustees of their rights, or knowingly negligently performed their duties. Based on this information and the factors identified by Verizon in the 2014 Report, it is possible to identify security elements for the above scenarios: - Software Inventory - checks for type, version and patch number of all software. - Absence of unnecessary software, accounts, ports, etc. system does not have software, accounts, open ports, etc. that is not used. - Updates and patches - update and install patches for software and OS.

- System file integrity - checks for suspected changes to system files and the appearance of new suspicious files in system locations, and report on such activity. - Anti-virus programs - effective anti-virus, anti-spyware and personal firewalls. - Security updates - checks for security updates and install them constantly.

- DEP, ASLR, EMET - use of Data Execution Prevention (DEP), Address space layout randomization (ASLR) and Enhanced Mitigation Experience Toolkit (EMET) technologies.

- Web application testing - checks web applications for potential vulnerabilities, code errors, and more. - Assests privacy - third parties do not have access to development materials (scripts, unused libraries, etc.). - Backup - process of automatically backing up data on an ongoing

basis.

- Employee IS training - required employee training events.

- Employee tests - periodic employee testing. - Traffic filtering - filtering traffic from approved services and

ports.

- Services separation - separation of critical system services from all other services (physically on another machine and having separate logic). - Admin control - system administrators are supervised by senior

management.

- Healthy passwords - use complex passwords.

- No-default-passwords - replace all default passwords.

- Black- andlor White IP lists - use black lists with known malicious IP addresses and $\backslash$ or white lists with trusted IP addresses.

- MFA - use of multi-factor authentification

But, as mentioned, not all threats are directly dependent on technical features. Information security system should be built to allow for a possible changes in configuration users and degree of confidentiality and value of information. At the same time, introduction of each new system element or changes conditions should not reduce achieved level of security as a whole.

As noted in Mitnick's work [4], users, intentionally or through lack of knowledge, are the greatest threat to information security. Siponen [6] notes that without the necessary knowledge and cooperation of users with the security staff or management department, adequate security measures become ineffective. This group is the most extensive and of greatest interest organization security point of view, as the actions of the subject can be predicted and necessary security measures taken, countermeasures in this case are directly dependent on the will of the organization security.
"Human factor" threats can be considered an entity having access (authorized or not) to information with regular security. The subjects, which actions can lead to information breach can be external and internal. External sources, in it's case, can be accidental or intentional and have different levels of incompetence. ENISA provides a comprehensive view [19] to such concept as cybersecurity culture (CSC), that refers to knowledge, beliefs, perceptions, attitudes, assumptions, norms, and values of people about cybersecurity in general and how they behave with information technology. CSC, in ENISA terms [19], covers familiar topics, including cybersecurity awareness, broader in scope and application, and to make cybersecurity an integral part of the employee's organizational life. This will help promote both the understanding and adoption of CSC programs in organizations. Understanding the impact of human psychology, sociological factors and cultural influences are essential to the development of a successful CSC.

In the existing literature, cybersecurity culture or, as sometimes called, information security culture (ISC) is an important component in ensuring security of information assets of organizations. In works such as Dhillon [2], the author defines ISC as behavior, values, and assumptions that provide information security, and researchers like Helokunnas [3] define ISC as a system in which motivation, direction, knowledge, and mental models interact. Van Nickerk and Vaughn Solms in their work [7] propose a conceptual model of information security culture. This model aims to identify the interactions between the various elements that make up the information security culture. The experiments carried out by Potiy [5] and help to decipher the concept of ISC into components. Thus, ISC can be defined by the following components:

- Staff

- Personnel Security

- IS Adoption

- Guidance

- Management Insurance

- Coordination

- Collaboration with IS department

- Collaboration with Management department

\section{Q-ANALYSIS FOR INFORMATION SECURITY DOMAIN AREA}

Q-analysis involves relatively simple calculations when approximate sets are determined and their ratios are estimated. No additional system information is required. Q-analysis technique provides an algebraic topological structure for data reduction that facilitates macroscopic conceptualization of the system, thus you can reduce indicators such as connectivity, eccentricity, and complexity.

The strength of communication between elements of the security system plays a significant role in determining the degree of interaction between elements. In the absence of a link between elements, system itself will be vulnerable for attacks. Systemic nature of the study area allowed us to determine $\Sigma$ - the set of threats and security measures that are related by the relation $\lambda$ and are the basis of the system. 
$\lambda$ is the Cartesian product of the sets $\mathrm{X}$ and $\mathrm{Y}$, where $\mathrm{X}=$ $\{\mathrm{x} 1, \mathrm{x} 2, \ldots, \mathrm{x} 13\}$ is the set of threats to the system,based on the above analysis for attack vectors and security measures:

$\mathrm{x}_{1}-\mathrm{POS}, . ., \mathrm{x}_{13}-$ Coordination

$\mathrm{Y}=\left\{\mathrm{y}_{1}, \mathrm{y}_{2}, \ldots, \mathrm{y}_{37}\right\}-$ security measures set:

$\mathrm{y}_{1}$ - Software Inventory , .., $\mathrm{y}_{37}$ - Collaboration with Management department

That is, the Cartesian product $\left(\mathrm{Y}_{\mathrm{i}}, \mathrm{X}_{\mathrm{k}}\right)$ shows that $\mathrm{Y}_{\mathrm{i}}$ is in relation to $\lambda$ with $\mathrm{X}_{\mathrm{k}}$, if $\lambda=1$ in this case and $\lambda=$ 0 otherwise. The relation between the elements of the sets $\mathrm{X}$ та $\mathrm{Y}$ can be represented as an incidence matrix $\Delta=$ $\left(\lambda_{\mathrm{ik}}\right)$, where $\lambda_{\mathrm{ik}}=1$, if $\left(\mathrm{Y}_{\mathrm{i}}, \mathrm{X}_{\mathrm{k}}\right) \varepsilon \lambda$ and $\lambda_{\mathrm{ik}}=0$ otherwise. The structural vector $\mathrm{Q}$, which is a direct result of the MCQA as stated by Duckstein [12], can be used to obtain additional information about the relationship between components

Algorithms for obtaining the q-common faces of all pairs of Y-simplexes for $\mathrm{K}_{\mathrm{y}}(\mathrm{X} ; \lambda)$, according to is : dimensions.

1. Assemble the matrix $\Delta \Delta^{\mathrm{T}}$ with $(\mathrm{mxm})$

2. Determine $\Delta \Delta^{\mathrm{T}}-\Omega$, where $\Omega=\left(\omega_{\mathrm{ij}}\right), \omega_{\mathrm{ij}}=1$ for $\mathrm{i}, \mathrm{j}=1,2, \ldots, \mathrm{m}$.

Using structural vectors it is possible to obtain and compare the degree (numerical value) of the complexity of relations. To do this, formula from [12] is used (1):

$$
\varphi(\mathrm{K})=\frac{2\left[\sum_{i=0}^{N}(i+1) Q_{i}\right]}{(N+1)(N+2)}
$$

of Q.

where $\mathrm{N}=\operatorname{dimK}-\mathrm{K}$ dimension; $\mathrm{Q}_{\mathrm{i}}-$ component

Since the individual properties of simplexes can be important for solving problems, it is necessary to determine the degree of integration of each simplex in the structure of the whole complex. For this there is the concept of eccentricity, which expresses the degree of isolation of the simplexes from each other. . This concept reflects both the relative importance of a simplex to a complex and the importance of a simplex as a connected element. The eccentricity of the simplex is determined by the following formula (2):

$$
\operatorname{Ecc}(\sigma)=\frac{q-\breve{q}}{\check{q}+1}
$$
with $\mathrm{P}_{\mathrm{j}}$

, where $q=\operatorname{dim} P_{i}, \check{q}-\max q$, where $P_{i}$ connects

The resulting structural vector according to the incidence matrix has the following form (3):

$$
Q=(0,0,0,0,0,0,0,0,0,3,8,6,37)(3)
$$

Most valueable $\operatorname{Ecc}(\sigma)$ for $\mathrm{X}$ and $\mathrm{Y}$ sets has following in contents of table 1

TABLE I: X AND Y SETS

\begin{tabular}{|c|l|}
\hline $\begin{array}{c}\text { Y - Secuirty } \\
\text { measures }\end{array}$ & \multicolumn{1}{|c|}{$\operatorname{Ecc}(\sigma)$} \\
\hline $\mathrm{y}_{4}-\mathrm{MFA}$ & 0,33 \\
\hline $\mathrm{y} 7-\mathrm{DLP}$ & 0,5 \\
\hline $\begin{array}{c}\mathrm{y} 13-\quad \text { Encrypted } \\
\text { information }\end{array}$ & 0,5 \\
\hline
\end{tabular}

\begin{tabular}{|l|l|l|}
\hline $\begin{array}{c}\text { y20 } \\
\text { trainings }\end{array}$ & Employee IS & 0,33 \\
\hline
\end{tabular}

\begin{tabular}{|c|l|}
\hline $\begin{array}{c}\mathrm{X}-\text { Secuirty threats } \\
\mathrm{x}_{1}-\end{array}$ & \multicolumn{1}{|c|}{$\operatorname{Ecc}(\sigma)$} \\
\hline Application Attack & 1 \\
\hline $\mathrm{x}_{2}-$ DOS attacks & 0,5 \\
\hline $\mathrm{x}_{3}-$ Insider Attack & 6 \\
\hline $\begin{array}{c}\mathrm{x}_{5}-\text { Physical Theft } \\
\text { or Loss }\end{array}$ & 2 \\
\hline $\begin{array}{c}\mathrm{x}_{6}-\text { Payment Card } \\
\text { Skimmer }\end{array}$ & -1 \\
\hline $\begin{array}{c}\mathrm{x}_{7}- \\
\text { espionage }\end{array}$ & 1 \\
\hline $\mathrm{x}_{8}-$ Malware & 1,25 \\
\hline $\mathrm{x}_{9}-$ POS & 1,75 \\
\hline $\begin{array}{c}\mathrm{x}_{10}-\quad \text { Personnel } \\
\text { Security }\end{array}$ & 0,75 \\
\hline $\begin{array}{c}\mathrm{x}_{12}-\text { Management } \\
\text { Insurance }\end{array}$ & 0,2 \\
\hline $\mathrm{x}_{13}-$ Coordination & -1 \\
\hline
\end{tabular}

\section{CONCLUSIONS}

This paper analyzes information leakage scenarios derived from 2014-2017 information leakage reports and the specifics of an information security culture that is relevant to human-related threats. As a result of the analysis, the necessary sets and ratios for the Q-analysis were determined. The mathematical apparatus of Qanalysis allows to study the topological, information and functional properties of information security systems. Based on the study of the structural connectivity of the system, it becomes possible to conduct a formal assessment of its level of functionality, which determines the ability to absorb external adverse factors at the expense of internal resources. This will effectively manage the decision-making process, improve the management of existing weak links. This paper analyzes information leakage scenarios derived from 2014-2017 information leakage reports and the specifics of an information security culture that is relevant to human-related threats. As can be seen in the work, the relationship between the security elements can be one of many, which helps to conclude that the use of a single security information from the specified in the work can lead to the use of the element with him in relation to or vice versa. This structure can be used as a basis for analyzing the information security systems. 


\section{REFERENCES}

[1] Архипов О.С. Щодо методики ідентифікації та оцінювання активів системи інформаційних те-хнологій , Захист інформації., №1 (50), 2011, с.42-47.

[2] Dhillon G. Managing information system security/ Dhillon G., London: Macmillan, 1997, pp 137-172.

[3] Helokunnas T. Information security culture in a value net. In: Engineering Management Conference, IEMC'03 on Managing Technologically Driven Organizations: The Human Side of Innovation and Change, New York: IEEE Press, 2003, pp. 190194.

[4] Mitnick K.D. The art of deception: controlling the human element of security, Wiley Publishing, 2002, p. 3.

[5] Potiy A. V. The prerequisites of information security culture development and an approach to complex evaluation of its level, Радіоелектронні і комп'ютерні системи, № 5, 2012, p. 72-77.

[6] Siponen M.T. Five dimensions of information security awareness, Computers and Society, 2001, pp $24-29$

[7] Van Niekerk J.F. Information security culture: A management perspective, Computers \& Security, 2010, p.478.

[8] 2014 Data Breach Investigation Report, Verizon Enterprise Solutions, 2013

[9] 2015 Data Breach Investigation Report, Verizon Enterprise Solutions, 2014

[10] 2016 Data Breach Investigation Report, Verizon Enterprise Solutions, 2015

[11] 2017 Data Breach Investigation Report, Verizon Enterprise Solutions, 2016

[12] L. Duckstein, S.A, Nobe / European Journal of Operational Research, 103 (1997), 411-425

[13] Малюк А.А. Информационная безопасность; концептуальные и методологические основы защиты информации. Учеб. пособие для вузов.-М: Горячая линия-Телеком, 2004, 280с.

[14] Кузнецов И.Н. Учебник по информационно-аналитической работе. Информация: сбор, защита, анализ. М.: Изд. Яуза, 2001.

[15] Чмора А.Л. Современная прикладная криптография. М.: "Гелиос АРВ", 2002.

[16] Садердинов А.А. и др. Информационная безопасность предприятия. М.: "Дашков и К", 2004.

[17] Черемных С.В., Семенов И.О. Ручкин В.С. Моделирование и анализ систем. IDEF-технологии: практикум, 2006.

[18] Cyber Security Culture in organisations, ENISA, 2017 